\title{
BACHELARD E SUA INTERPRETAÇÃO FILOSÓFICA DA TEORIA DA RELATIVIDADE
}

\author{
BACHELARD AND HIS PHILOSOPHICAL INTERPRETATION OF THE \\ RELATIVITY THEORY
}

\author{
DAVID VELANES ${ }^{1}$ \\ Universidade Federal da Bahia (UFBA) - Brasil \\ dvelanes@gmail.com
}

GABRIEL KAFURE DA ROCHA ${ }^{2}$

Instituto Federal do Sertão Pernambucano (IF Sertão - PE) - Brasil

gabriel.rocha@ifsertao-pe.edu.br

\begin{abstract}
RESUMO: A Teoria da Relatividade abalou as noções mais fundamentais da física e da filosofia consideradas como absolutas até o início do século XX. Esse contexto de reforma epistêmica fez com que filósofos e cientistas repensassem a epistemologia para buscar fundamentos mais adequados à mecânica de Einstein. Gaston Bachelard trouxe em sua filosofia científica uma importante reflexão acerca das inovações da física contemporânea ao ter como seu projeto filosófico dar às ciências os fundamentos necessários para seu melhor entendimento. O presente trabalho busca caracterizar as ideias do filósofo francês de forma sistemática e pôr em destaque um filósofo por vezes esquecido nos estudos acerca da filosofia da física.
\end{abstract}

PALAVRAS-CHAVE: Bachelard. Teoria da Relatividade. Ruptura Epistemológica.

ABSTRACT: The theory of relativity shook notions regarded prior to the early twentieth century as absolute and fundamental in both physics and philosophy. This context of epistemic reform has led philosophers and scientists to rethink epistemology to seek more adequate foundations for Einstein's mechanics. Through his scientific philosophy, Gaston Bachelard offered an important reflection on the innovations of contemporary physics; his philosophical project was to give the sciences the necessary foundations for their better understanding. The present work seeks to characterize the ideas of the French philosopher systematically and to highlight a philosopher sometimes forgotten in studies of the philosophy of physics.

KEYWORDS: Bachelard. Theory of Relativity. Epistemological Break.

\section{INTRODUÇÃO}

"Os resultados das pesquisas científicas forçam frequentemente uma alteração do ponto de vista filosófico sobre problemas que vão além da própria ciência”. Com base nessa afirmação de Einstein \& Infeld (2008, p. 52), na obra

\footnotetext{
${ }^{1}$ Doutorando em Filosofia pela Universidade Federal da Bahia, bolsista Capes.

${ }^{2}$ Doutor em Filosofia pelo Programa de Pós-Graduação em Filosofia da UFRN, Professor de Filosofia do IF Sertão - PE.
} 
Evolution of physics (1938), podemos afirmar que, por um lado, cabe à filosofia a tarefa de se ocupar das questões que ultrapassam as fronteiras das ciências, com a finalidade de criar interpretações pelas quais se possa compreender a realidade em um sentido mais profundo. Por outro, indica-nos também que é dever da filosofia se atualizar perante às inovações introduzidas pelo saber científico.

Essa última consideração nos leva a uma das teses de Gaston Bachelard (1884-1962), para quem a filosofia deve se orientar com base no conhecimento das ciências, para que possa oferecer fundamentos mais adequados às teorias científicas que insurgem como grandes rupturas com relação aos saberes do passado. Em sua obra La philosophie du non (1940), o filósofo francês expressa bem essa concepção ao dizer que "a ciência instrui a razão. A razão deve obedecer à ciência, à ciência mais evoluída, à ciência em evolução” (BACHELARD, 1983, p. 144).

A epistemologia bachelardiana foi edificada no contexto da revolução científica causada pelas geometrias não euclidianas e pelas mecânicas não newtonianas. É possível afirmar, sem dúvida, que os conceitos apresentados por estas últimas, nas quais se inclui a Teoria da Relatividade, exerceram uma influência indiscutível nas ideias do filósofo francês.

Bachelard, em seu artigo La dialectique philosophique des notions de la relativité (1949), que tomamos como fio condutor de análise deste trabalho, apresenta importantes considerações acerca de suas ideias filosóficas a respeito da Relatividade. Nesse artigo, o filósofo francês retoma algumas considerações mencionadas em sua obra La valeur inductive de la relativité, de 1929, a qual o autor expõe as provocações relativistas perante o espírito científico da época.

Segundo Laclos (2005), a obra bachelardiana supracitada, que tem sido pouco estudada ${ }^{3}$, é relevante para o entendimento acerca de como a França do século XX recepcionou a mecânica de Einstein. De nossa parte, acrescentamos que também o capítulo segundo de Le nouvel esprit scientifique (1934), - La mécanique non-newtonienne -, e o artigo supracitado de 1949, constituem o epicentro das considerações bachelardianas a respeito da mecânica relativista, pois também incorporam elementos importantes da recepção francesa desta teoria no início do século passado.

Cumpre observar que o pensamento de Bachelard é assistemático, que impõe, portanto, uma análise sistemática, não necessariamente linear de seus escritos. À vista disso, este trabalho não tem como objetivo construir uma possível

\footnotetext{
${ }^{3}$ Estamos convencidos de que a afirmação de Laclos (2005) é questionável, na medida em que diversos comentaristas do pensamento de Bachelard têm se dedicado a esclarecer os fundamentos filosóficos bachelardianos da Teoria da Relatividade, incluindo, em suas análises, a obra La valeur inductive de la relativité. Concordamos com Alunni (2018, p. 27), quando diz que, embora essa obra seja pouco comentada, ainda assim houve importantes comentários de nomes que foram exceção, tais como, Jean Hyppolite, em "L'épistémologie de la relativité" (1962), Mario Castellana em seu texto "Spazio et tempo nell'epistemologia di Gaston Bachelard", Daniel Parrochia, em seu artigo "La lecture bachelardienne de la théorie de la relativité", de (2005). Pode-se conferir também Vincent Bontems "A relatividade filosófica", na seção I da parte segunda de sua obra Bachelard (2010). Além dos estudos citados por Alunni (2018), podemos incluir no Brasil também e o artigo de Carvalho Filho (2016), intitulado "Bachelard e o caráter indutivo da Teoria da Relatividade".
} 
evolução das ideias do filósofo francês acerca da Relatividade mediante uma análise histórica-linear de suas obras epistemológicas, mas o de clarificar, por meio de seu campo argumentativo, sua interpretação filosófica acerca da mecânica de Einstein.

Um aspecto relevante para o objetivo aqui pretendido é elucidar o contexto ao qual Bachelard estava inserido e pelo qual ele edifica sua interpretação da Teoria da Relatividade. É em crítica com as concepções filosóficas de Émile Meyerson (1859-1933) e Henri Bergson (1859-1941), teóricos importantes na filosofia científica francesa, que se manifesta inicialmente a interpretação bachelardiana da mecânica relativista.

\section{A Crítica a Meyerson e a Bergson}

Em relação a Meyerson, a crítica de Bachelard tem como base o aspecto inédito da física relativista, que, segundo ele, provoca uma ruptura brusca com a física clássica no início do século passado.

Para Meyerson (1951), os séculos XIX e XX, embora tenham apresentados importantes transformações na cultura científica, não constituem momentos de descontinuidades do saber científico. Sua posição filosófica positivista parte da ideia segundo a qual o conhecimento científico é uma continuidade do senso comum, isto é, um aperfeiçoamento das noções mediante um processo cumulativo de ideias pelas quais se obtém a instauração de conhecimentos mais complexos e elaborados. Bulcão (2009) esclarece que:

Émile Meyerson defendia uma filosofia que pregava a eternidade de seus princípios e de suas questões. Implicitamente via-se a defesa de um progresso contínuo da ciência, no qual as teorias eram uma continuidade das anteriores. Meyerson se apoiava numa filosofia cujos princípios eram "os absolutos da Razão". (p. 30).

Segundo o autor de Identité et réalité (1951), tanto o senso comum quanto o saber científico são prefigurados pelos "cânones eternos do intelecto humano". Dessa forma, seu pensamento estabelece uma concepção segundo a qual a razão possui princípios absolutos e, ao instituir o princípio de identidade como uma das teses centrais de seu pensamento, Meyerson pretendeu deduzir os princípios da Relatividade com base na mecânica clássica. Essas concepções são contestadas por Bachelard, que se opõe fortemente ao introduzir a sua noção de ruptura epistemológica.

Ainda que no século XX tenha ocorrido um predomínio das concepções positivistas acerca do desenvolvimento do saber científico, como as de Meyerson, a filosofia científica de Bachelard se apresenta na contracorrente das ideias prevalecentes dessa época, pois nos traz a análise a respeito da Teoria da Relatividade como a prova de uma eminente descontinuidade epistêmica, que abala as filosofias imobilistas, como também é o caso da crítica bachelardiana a Bergson. 
A crítica de Bachelard a Bergson vai de encontro às concepções deste autor a respeito da continuidade do tempo. Segundo Bachelard (1994, p. 12), a filosofia bergsoniana se trata de uma filosofia imobilista, na medida em que escreve o presente no passado, isto é, faz com que "o passado continue a ser a substância do presente, ou, em outras palavras, o instante presente nunca seja outra coisa que não o fenômeno do passado". Assim, o presente, na filosofia bergsoniana, não é criador, mas "uma continuidade do ser que evolui. Uma vida contínua pelo germe, ao destino, um elã obrigatoriamente isento de interrupções" (BACHELARD, 1994, p. 16).

Embora Bachelard reconheça a profundidade das concepções de Bergson ${ }^{4}$, ele as apresenta como contrárias à sua ideia de tempo, concebido como uma sequência de instantes descontínuos. É possível afirmar que a noção de continuidade temporal bergsoniana não pode corresponder à visão bachelardiana acerca da história das ciências a qual se estabelece por interregnos, lacunas ou rupturas epistemológicas. Bachelard (1994, p. 16) diz que na tese de Bergson "o ser, o movimento, o espaço e a duração não podem comportar lacunas".

Haveria certa contradição entre a tese do "filósofo da ruptura", que afirma a descontinuidade histórica do saber, e a ideia do autor de L'évolution créatrice (1907) segundo a qual, no mundo, e por consequência na história, existe uma continuidade temporal manifesta. Podemos dizer que essas considerações tendem a anular o caráter inédito da Teoria da Relatividade, na medida em que esta surge no campo do saber científico sem antecedentes no passado (Bachelard, 1929), como destacaremos ainda neste trabalho.

Em L'intuition de l'instant (1932), Bachelard confere à Teoria da Relatividade a prova do abalo da tese bergsoniana. A crítica de Einstein, especialmente aquela que é feita à noção de simultaneidade, teria trazido um despertar do "sonho dogmático" acerca da ideia de duração objetiva. Assim, contra Bergson, o autor afirma que:

O que o pensamento de Einstein chama de relatividade é o lapso de tempo, é o "comprimento" do tempo. Este comprimento é revelado em relação ao seu método de medição. Dizem-nos que ao fazer uma viagem de ida e volta no espaço a uma velocidade bastante rápida, encontraríamos a terra envelhecida alguns séculos, enquanto teríamos marcado algumas horas em nosso próprio relógio em alcance em nossa corrida. Muito menos tempo seria a viagem necessária para ajustar nossa impaciência ao tempo que Bergson postula como fixo e necessário para derreter o pedaço de açúcar no copo de água. (BACHELARD, 2010. p. 32).

Bachelard (2010) lança mão da "autoridade" da ciência sobre a filosofia ( $C f$. BACHELARD, 1983, p. 144), para desautorizar a tese bergsoniana, caracterizandoa como inadequada. Seu argumento é de que a Relatividade apresenta o lapso de tempo com base em dados científicos. Dessa forma, a filosofia deve se adequar aos novos conceitos das ciências. O filósofo não pode se recusar às lições das

4 "[...] digamos desde já que do bergsonismo aceitamos quase tudo, exceto a continuidade" (BACHELARD, 1994, p. 16). 
ciências, ele deve pensar a ciência em sua totalidade. A ciência relativista estabelece, doravante, o instante como absoluto, e não mais a duração. O instante é a síntese no ponto de encontro entre o espaço e o tempo, um ponto do espaçotempo.

Embora a base dos argumentos bachelardianos contra Bergson sejam de ordem mais metafísica do que epistemológico-histórica, diferentemente do que ocorre com a crítica a Meyerson, podemos notar que, nos dois casos, uma das preocupações predominantes das argumentações de Bachelard é a de sustentar e preservar sua tese da ruptura, a qual confere à Relatividade uma natureza inteiramente inédita na história do conhecimento científico.

\section{A RELATIVIDADE COMO RUPTURA E SÍNIESE HISTÓRICA}

A teoria relativista aparece no século XX como uma ciência sem precedentes na história do saber (BACHELARD, 1929), uma vez que seus conceitos não são prefigurados pelas noções de outrora, como poderia sugerir uma análise ingênua acerca da história epistemológica da física. A mecânica de Einstein, como um dos fatos que revolucionou as ciências, possibilitou concepções inovadoras na epistemologia.

Segundo Bachelard (1999), a mecânica de Newton se apresentou na história como um sistema inteiramente pronto e fechado em seus princípios mais fundamentais. Diante deste sistema físico, "[...] não podíamos sair a não ser por arrombamento" (p. 46). Isso quer dizer que não pode equivaler uma transição da mecânica newtoniana para a mecânica relativista, porquanto ambas se tratam de sistemas distintos, como bases matemáticas diferentes. Conforme o filósofo francês, somente após muitos desmontes nas matemáticas intrínsecas ao sistema de Einstein seria possível chegar ao sistema de Newton. A seguinte passagem de Le nouvel esprit scientifique (1934) é bastante esclarecedora quando ele diz que:

[...] mesmo sob a relação simplesmente numérica, estamos errados, acreditando, quando vemos no sistema newtoniano uma primeira aproximação do sistema einsteiniano, porque as sutilezas relativistas não decorrem de aplicação refinada dos princípios newtonianos. Não podemos, portanto, dizer corretamente que o mundo newtoniano prefigura em suas grandes linhas o mundo einsteiniano. É depois, quando se está instalado no pensamento relativista, que reencontramos os cálculos astronômicos da Relatividade — por mutilações e abandonos — os resultados numéricos fornecidos pela astronomia newtoniana. Não há, pois, uma transição entre o sistema de Newton e o sistema de Einstein. Não se vai do primeiro ao segundo acumulando conhecimentos, redobrando de cuidado nas medidas, retificando ligeiramente os princípios. (BACHELARD, 1999, p. 46).

Uma interessante observação destacada por Bachelard (1999) é que a mecânica relativista não exibe uma mesma relação com a realidade comum à qual se debruçava a física clássica, na medida em que se encontra afastada dos valores pragmáticos, isto é, na Relatividade, parte-se do matemático para o real e não deste para aquele. Há, portanto, uma inversão no vetor epistemológico. 
Similarmente, Einstein (1999) explica que é incompleta a visão segundo a qual a evolução da ciência é concebida como um processo indutivo, que parte do real, para que, em seguida, uma grande quantidade de experiências possam ser resumidas em uma teoria, como se sua evolução fosse o resultado de "um trabalho de catalogação, um produto meramente empírico" (EINSTEIN, 1999, p. 101), uma vez que, dessa forma, se desconsidera o trabalho do pensamento dedutivo no processo de evolução do saber. Para o físico alemão, nas ciências que se encontram em um grau maior de desenvolvimento, os progressos já não são determinados por meio de uma simples atividade de ordenação da experiência, mas mediante um trabalho cujo ponto de partida são os axiomas. ${ }^{5}$

Ademais, outra consideração importante destacada por Bachelard (1999) e Einstein (1999) é a de que ambos os sistemas físicos se fundamentam em geometrias distintas. Enquanto a física de Newton tem como base a geometria de Euclides, a física de Einstein se instaura sobre a geometria não euclidiana de Riemann. Em La valeur inductive de la relativité (1929), Bachelard é enfático quanto a essa distinção ao asseverar que:

A mecânica newtoniana exige um espaço absoluto euclidiano. Entretanto, a partir do sistema de Einstein, se nos colocamos em um espaço-tempo euclidiano, não temos mais o campo da gravitação e, por consequência, temos mais a atração newtoniana. (BACHELARD, 1929, p. 47).

Segundo Velanes (2018), não é por acaso que Bachelard considera a Teoria da Relatividade como ponto paradigmático de descontinuidade epistêmica no início do século XX, uma vez que a mecânica quântica também realizou uma ruptura epistemológica ainda na primeira metade do mesmo século. O fato considerado pelo autor é que, enquanto a mecânica relativista emerge diretamente como um sistema completo e acabado, a mecânica quântica precisou de duas décadas para adquirir um formalismo matemático coerente. Conforme Heisenberg (2007), mais precisamente, em 1925, por meio de dois desenvolvimentos diferentes, a saber, com o princípio de complementaridade de Bohr e com a equação de Schrödinger. Entretanto, ambos os sistemas físicos devem ser considerados como provas de importantes inovações conceituais que revolucionaram a episteme no século passado.

\footnotetext{
${ }^{5} \mathrm{Na}$ Revue Études Philosophiques, Bachelard afirma em um curto e raro artigo de 1940 intitulado Pensamento Axiomático: "I. A distinção entre axiomas e postulações tem prejudicado as realidades das idéias e a estrutura da razão. Ela acentua a oposição entre razão e experiência e a difícil vinda de uma organização racional da experiência. De fato, essa distinção se deve à arbitrariedade. Por outro lado, é uma boa passagem para as noções fundamentais de função e não-realismo. É somente por essa função que se deve examinar uma organização axiomática. II. - Estudo das características gerais axiomáticas. Não há axiomas absolutos. Nem nada que dê axiomas relativos. É sempre possível que três características sejam suficientes para a relatividade dos postulados. Um sistema de postulados ou axiomas deve ser: $1^{\circ}$ coerente; $2^{\circ}$ completo; $3^{\circ}$ Não-tautológico. III. - Cada uma das características é elenco de critérios da necessidade de estudar a validade e fecundidade. Por este propósito se propõe, por outro lado, comentar como joga a dialética da origem das postulações e a compreensão do nascimento da geometria não-euclidiana. IV - O desenvolvimento deve preparar duas conclusões metafísicas que podem se intitular: o racionalismo dialético e a razão empírica." (BACHELARD, 1940, p. 22-23).
} 
Portanto, as rupturas conceituais causadas pela mecânica relativista (e também pela mecânica quântica) impuseram renovações nas ideias filosóficas então existentes ao exigir novas fundamentações para a física contemporânea.

Conforme Bachelard (1966), a Relatividade constitui, ela mesma, uma revolução da razão. Com essa teoria de Einstein, "[...] a ciência experimenta então o que Nietzsche chama de 'tremor de conceitos' como se a Terra, o Mundo e as coisas tivessem tomado outra estrutura desde que colocadas as explicações em novas bases" (BACHELARD, 1972, p. 130). As noções científicas que sofreram o "tremor nietzschiano" causaram uma repercussão nas filosofias do conhecimento modernas e nas concepções positivistas.

A ideia de "tremor conceitual" também é apresentada em La formation de l'esprit scientifique (1938), quando o autor assevera que a teoria einsteiniana, em 1905, causou abalos nos conceitos mais sedimentados na cultura científica e acreditados como inabaláveis, que determinaram uma ruptura epistemológica no desenvolvimento do saber científico. Segundo Bachelard (1977, p. 9), "a partir desta data, a razão multiplica suas objeções, ela dissocia e religa as noções fundamentais, propõe as abstrações mais audaciosas. Ideias das quais uma única bastaria para ilustrar um século".

Convém notar que, segundo Bachelard (1963, 1972, 1983, 1999), a ruptura entre física clássica e física relativista não é "cataclísmica". A mecânica clássica e o senso comum possuem seus lugares na complexidade dos valores epistemológicos do novo espírito científico. Entre a física de Newton e a física de Einstein existe uma dialética envolvente. A Relatividade não consistiu em uma aniquilação absoluta das ideias estabelecidas pela física clássica, mas em uma grande síntese histórica, na medida em que pôde explicar os fenômenos para os quais a mecânica newtoniana se revelou ineficaz, e, ao mesmo tempo, mantê-la nos campos de atuação para os quais elabora explicações científicas bem sucedidas.

Em suma, foi mediante um "tremor de conceitos" que a organização racional do conhecimento científico da física dialetizou suas noções mais fundamentais. A teoria de Einstein institui um diálogo direto entre racionalismo e empirismo, na medida em que fez corresponder uma síntese entre ambas as metafísicas, isto é, entre um racionalismo matemático e o empirismo técnico (BACHELARD, 1972). A síntese histórica instaurada pela mecânica relativista implicou uma verdadeira imbricação entre essas filosofias.

Se pudéssemos então traduzir filosoficamente o duplo movimento que atualmente anima o pensamento científico, aperceber-nos-íamos de que a alternância do a priori e do a posteriori é obrigatória, que o empirismo e o racionalismo estão ligados, no pensamento científico, por um estranho laço, tão forte como que une o prazer à dor. Com efeito, um deles triunfa dando razão ao outro: o empirismo precisa de ser compreendido; o racionalismo precisa de ser aplicado. Um empirismo sem leis claras, sem leis coordenadas, sem leis dedutivas não pode ser pensado nem ensinado; um racionalismo sem provas palpáveis, sem aplicação à realidade imediata não pode convencer plenamente (BACHELARD, 1983, p. 4-5). 
É importante notar que a ideia de síntese histórica bachelardiana se trata de uma síntese transformante (BACHELARD, 1965, 1999), pela qual, no movimento dialético do saber científico, as teorias mais atuais e complexas englobam as de outrora cuja simplicidade se mostrou evidente no século XX. Essa dialética da qual Bachelard nos remete não pode ser compreendida à maneira da filosofia tradicional, especialmente à de Hegel (Cf. BACHELARD, 1983, p. 135-136). Tratase da dialética do movimento do saber científico, própria das ciências, na qual os valores de oposição não são excludentes, mas complementares.

A mecânica relativista se opõe sem antagonizar com a mecânica clássica permitindo que ambas possam coexistir simultaneamente no novo espírito científico. Porém, segundo Bachelard (1999), a astronomia de Einstein, em seu caráter de complexidade relativo às noções clássicas, envolve a astronomia de Newton cujos conceitos são mais simples, tornando-a um caso particular. Dessa forma, alargam-se os quadros do saber na medida em que se complexifica os conceitos científicos instaurando novas formas conceituais. ${ }^{6}$

\section{A TEORIA DA RELATIVIDADE E AS RUPIURAS CONCEITUAIS}

Conforme afirmamos, a revolução da física relativista implicou em "tremores" das noções de base da ciência clássica. Mas, "quais são então os conceitos que tremem?" (BACHELARD, 1972, p. 115). No mesmo parágrafo dessa citação o autor responde que foram "os conceitos de espaço absoluto, de tempo absoluto e de velocidade absolutas".

Segundo Bachelard (1972, 1999), as noções clássicas de espaço e tempo são abaladas pelo advento da mecânica relativista uma vez que deixam de serem absolutas. Esses conceitos físicos passam a exigir uma experiência precisa, e não mais a experiência comum, isto é, passam a ser pensadas por meio de peculiares instrumentos técnicos de medição, que são, eles mesmos, inovações da física contemporânea.

"O método de referência, essencialmente discursivo, deverá, portanto, pensar-se sempre explicitamente em relação com o fenômeno" (BACHELARD, 1972, p. 134). Essa nova forma de pensar os conceitos de espaço e tempo se caracteriza como um fato notório de ruptura conceitual, de atualização das noções e evidencia o caráter inédito da física relativista como parte de um novo espírito científico.

Segundo Bachelard (1972, p. 135), as novas representações do espaço apresentadas pelas mecânicas contemporâneas "devem lutar contra a clareza

\footnotetext{
6 "Em resumo, se lançamos uma vista geral sobre as relações epistemológicas da ciência física contemporânea e da ciência newtoniana, veremos que não há desenvolvimento das antigas doutrinas para as novas, mas muito antes envolvimento dos antigos pensamentos pelos novos. As gerações espirituais procedem por encaixes sucessivos. Do pensamento não-newtoniano ao pensamento newtoniano, não existe contradição, há somente contração. É essa contração que nos permite encontrar o fenômeno restrito ao interior do númeno que o envolve, o caso particular no caso geral, sem que nunca o particular possa evocar o geral. Doravante, o estudo do fenômeno depende duma atividade puramente numenal; é a matemática que abre os novos caminhos para a experiência" (BACHELARD, 1999, p. 62).
} 
ofuscante das intuições comuns, contra a formalização também rápida do criticismo kantiano". Um conceito claro tomado como evidente, sem a aplicação prévia da dúvida, pode obstaculizar o saber. De forma que se torna

[...] necessário que o homem de ciência reaja contra o passado de sua própria cultura. Uma espécie de psicanálise, de uma autopsicanálise, deve ser praticada para prevenir o espírito de ser impedido por suas próprias ideias claras. Uma ideia clara sobre um domínio de pesquisas pode deixar de ser esclarecedora em outro domínio. (BACHELARD, 1972, p. 102).

O filósofo francês reflete a respeito da noção de simultaneidade da física clássica, que, segundo ele, não foi submetida por Kant ao crivo da crítica. Essa noção foi posta em dúvida por Einstein, isto é, a um exame crítico acerca de suas limitações perante a Relatividade, no sentido de estabelecer uma retificação discursiva desse conceito que foi aceito como inquestionável durante séculos. Por meio dessa dúvida, Bachelard (1972) diz que a noção de simultaneidade foi possível de ser verificada mediante experiências objetivas e mais precisas.

Aqui, consiste um exemplo acerca de uma das ideias fundamentais do racionalismo aplicado, qual seja, de que os conceitos não se restringem apenas ao uso da razão, mas se verificam na experiência como forma de construção do real. Assim, Bachelard propõe uma retificação do empirismo e racionalismo tradicionais. O mundo objetivo deve ser, doravante, considerado como os fatos verificados, pois se trata do "mundo que se desprende dos pensamentos verificados pela ciência de nosso tempo" (BACHELARD, 1972, p. 136).

Segundo ele [Bachelard], a relatividade, ao desmaterializar a realidade, mostra, por um lado, que nenhuma existência pode ser dada a nós em si mesma; por outro lado, essa essência é sempre uma "função da relação". O mundo é realmente mais do que "minha verificação" e o resultado dessa operação é sempre um relacionamento. Bachelard traça as rotas antigas para as novas vistas. A noção de força, primeiro atribuída ao sujeito, tornase uma relação na qual o esforço do agente e a resistência de um objeto são equilibrados; o conceito newtoniano de gravidade torna-se, de propriedade individual de um corpo, sua atração mútua (LACLOS, 2005, p. 58 - grifos nossos).

Bachelard (1999) demonstra que a noção de simultaneidade adquiriu uma complexidade muito maior em relação à sua forma conceitual apresentada pela mecânica clássica. Na Teoria da Relatividade, essa noção se distanciou das intuições da vida corriqueira e da experiência sensível e assumiu uma base inteiramente matemática. Doravante, foi preciso instituir uma experiência altamente especificada por meio de instrumentos técnicos de medição com o uso de sistemas de referências para se trabalhar com esse conceito. Com Einstein, a simultaneidade deixa de ser um conceito absoluto. Ela é, doravante, pertencente a um racionalismo aberto que dialoga com a experiência técnica. A simultaneidade passa a ser uma noção também experimental (BACHELARD, 1972).

Segundo Bachelard (1972), a transmutação da noção de simultaneidade implica diretamente na modificação do conceito de tempo absoluto da física 
newtoniana, porquanto a contextura temporal é correlata com a contextura espacial que, por sua vez, encontra-se ligada com a simultaneidade em uma determinada experiência física. Desta forma, o conceito clássico de tempo se retifica, assim como o conceito clássico de espaço.

Ambos os conceitos passam a ser reconstruídos a partir da "solidariedade das experiências sobre o espaço e sobre a simultaneidade" (BACHELARD, 1972, p. 138). Assim, a partir da crítica a esses conceitos, o próprio físico alemão explica que "a Teoria da Relatividade torna natural e explícita a visão quadridimensional do "mundo", pois, de acordo com esta teoria, o tempo deixa de ser independente" (EINSTEIN, 1999, p. 50).

Um interessante esclarecimento elaborado por Paty (2008, p. 59) é que a crítica de Einstein em relação à noção de simultaneidade instituiu uma elaboração inteiramente nova a respeito das noções de espaço e tempo - o espaço-tempo -, para que se pudesse estar de acordo com as demais ideias da física. "Einstein acabava de se dar conta, de alguma maneira, de que a física, no estado em que se encontrava, doravante, não satisfazia mais com o que havia de arbitrário nas definições de Newton". Com base nessa mesma problemática, Bachelard (1972) acrescenta que os conceitos de espaço e tempo absolutos são então abandonados cedendo lugar a novas formas conceituais que implicam em ontologias regionais de cada ciência e saber.

Bachelard informa o conceito sintético de espaço-tempo se encontra fundado em bases inteiramente algébricas pelas quais não se permitem associações com as imagens corriqueiras da experiência comum. Ou seja, implica abandonar não somente as imagens e as intuições vulgares, mas também devaneios de falsa profundidade acerca do conceito de espaço-tempo. Com a Relatividade, o espírito científico estabelece novas construções conceituais objetivas acerca da realidade. Bachelard (1972) diz que "só pode designar corretamente a renovação racionalista que implicam as doutrinas de Einstein fundando-se sobre a síntese do algebrismo e da experiência científica" (p. 138).

A cosmicidade da física relativista não depende da implicação do movimento dos observadores e isso se dá pelo fato de que, no universo, uma constante assinalável é a velocidade da luz, que é a mesma em todas as direções, qualquer que seja o movimento relativo dos observadores. Contudo, essa constante não é tampouco absoluta, é preciso reconstruir incessantemente o espaço-tempo de uma experiência científica a partir da referência.

Einstein (1999, p. 28) explica que "cada corpo de referência (sistema de coordenadas) possui seu tempo próprio. Uma especificação temporal só tem sentido quando se indica o corpo de referência ao qual esta indicação se refere". Todavia, "antes da Teoria da Relatividade, a física sempre admitia tacitamente que o significado das indicações de tempo era absoluto, isto é, que elas não dependiam do estado do corpo de referência".

Outro conceito síntese a que Bachelard se refere em sua interpretação da Relatividade e o apresenta como inovação é o de massa-energia ao qual corresponde uma homogeneidade algébrica antes não estabelecida. Os conceitos 
de massa e energia eram tomados como absolutos pela física clássica. Bachelard (1972) diz que "agora é preciso estabelecer entre eles uma relação profunda, ontológica. Só a matemática relativista pode estabelecer essa nova ontologia de massa-energia" (p. 144). Pois, como aqui é o pensamento algébrico que fundamenta esse novo conceito orientando a experiência, a noção de massaenergia apresenta então uma relação abstrato-concreta que dialetiza racionalismo e realismo numa síntese.

Quando o racionalismo instruído mantém contato com o real por símbolos condensados experimenta, aqui novamente, um grande repouso do espírito. [Esses] símbolos não têm nada de místico. Eles são translúcidos para o matemático e receptivos ao físico. As fórmulas unitárias da Relatividade generalizada são de sínteses filosóficas que reúnem o racionalismo e o realismo. (BACHELARD, 1972, p. 135).

Mas, e o conceito de velocidade absoluta o qual, segundo Bachelard, em seu artigo La dialectique philosophique des notions de la relativité (1949), também teria sofrido um "tremor nietzschiano"? Cumpre destacar que nesse artigo o autor omite uma reflexão acerca de tal noção, diferentemente dos conceitos de espaço e tempo absolutos, por exemplo. Todavia, podemos encontrar uma explicação a respeito da noção de velocidade em sua obra Le nouvel esprit scientifique (1934), na qual o filósofo ressalta que esse conceito permanece ainda em sua forma simplificada nos domínios da mecânica relativista. Bachelard (1999) diz que:

A preocupação de complexidade não se apresenta sempre tão claramente, e há conceitos ainda simples cuja complicação se poderia talvez correr o risco de prever. Far-se-ia sentir assim, na sua origem, a perturbação psicológica suscitada pela dúvida sobre a objetividade dos conceitos de base. Tal nos parece ser o caso do conceito de velocidade. Esse conceito saiu quase indene das manipulaçôes relativistas, ainda que o fato duma velocidade máxima não tenha podido ser inteiramente legitimado. (p. 53. - grifo nosso).

Segundo ele, a noção de velocidade não tem sido pensada mediante uma experiência precisa como ocorre com as outras noções já assinaladas neste trabalho. ${ }^{7}$ Portanto, podemos dizer que o conceito de velocidade não teria sofrido uma "mutação conceitual", uma ruptura brusca ou ainda um "tremor", como, por exemplo, as noções de massa, espaço, tempo, simultaneidade e tantas outras noções assinaladas pelo filósofo em sua epistemologia. Nesse sentido, podemos questionar se não haveria aqui uma contradição entre as afirmações de Bachelard apresentadas na obra de 1934 e no artigo de 1949? Teria o autor mudado de concepção em seu texto de maior maturidade, ou teria ele se equivocado quanto à afirmação de que o "tremor conceitual" também abalou a noção de velocidade? Se sim, por que não nos ofereceu um argumento em seu artigo?

\footnotetext{
${ }^{7}$ Para conferir a discussão do filósofo francês acerca desse conceito, ver Bachelard (1999, p. 5357).
} 


\section{RACIONALISMO APLICADOCOMO FILOSOFIA MAIS ADEQUADA}

Para não perder nada das lições filosóficas da ciência, as duas noções de invariância e conservação [da Relatividade] devem ser sintetizadas na filosofia abstrato-concreta, instituindo um laço de união, na forma de uma conservação e invariância. Essa é uma dupla filosófica que seria mutilada se fosse interpretada como uma filosofia monodrômica, como uma filosofia de mão única, seja no sentido racionalista, seja no sentido realista. (BACHELARD, 1972, p. 145).

Por não ser uma filosofia de mão única, mas uma filosofia do diálogo entre razão e experiência - um racionalismo aplicado -, Bachelard destaca que há uma ressignificação dos conceitos da filosofia empirista e da filosofia racionalista, antes tomados como absolutos, o que implica, com a Relatividade, a instituição de uma nova realidade científica cuja criação parte da matemática para a experiencia técnica.

Convém notar que Bachelard toma a análise histórica dos conceitos físicos como ponto catalisador para edificar suas próprias considerações filosóficas, contrapondo-as com as filosofias tradicionais. É desse modo que, para ele, as noções de espaço e tempo apresentadas por Kant não podem corresponder como fundamentos para a Relatividade, na medida em que esses conceitos não só perderam seu caráter apriorístico absoluto, como também já não podem ser entendidos como formas puras da sensibilidade a partir das inovações científicas do século passado.

[...] a noção de espaço-tempo, proposta por Lorentz, tal como foi aperfeiçoada por Einstein, aparece como a priori, funcionalmente a priori, que permite informar uma experiência eletromagnética precisa (BACHELARD, 1972, p. 140). ${ }^{8}$

Citando Brunschvicg, Bachelard (1972) diz que no âmbito da nova física, "[...] o progresso relativo a Kant foi ter transposto a síntese a priorido plano da intuição ao plano da inteligência” (p. 139). Essa ideia já aparece anteriormente na obra La philosophie du non (1940) que, embora a discussão nesta obra seja predominantemente voltada para a natureza dos objetos quânticos, o autor igualmente informa que para satisfazer o pensamento científico contemporâneo será "[...] necessário fazer ascender as duas formas da intuição sensível até ao entendimento, deixando à sensibilidade o seu papel puramente afetivo, o seu papel de auxiliar da ação comum" (BACHELARD, 1983, p. 103).

\footnotetext{
8 “[...] Procura todas as oportunidades para determinar as variações da teoria do conhecimento, pois endossa a observação de Lorentz de que a determinação de noções fundamentais exigia uma teoria do conhecimento. É no centro da dialética da informação experimental e da informação racional que colocou o racionalismo brunschivicguiano. Aí, neste campo magnetizante de categorias, neste campo gravitacional experiências, surgiu uma grande filosofia da cultura objetiva do pensamento cientista" (BACHELARD, 1972, p. 187).
} 
Com efeito, as mecânicas contemporâneas instituíram uma nova forma de racionalismo. A Relatividade instituiu um racionalismo culto (em La philosophie du non (1940), Bachelard usa a expressão racionalismo complexo) como expressão de um recomeço do pensamento racional que rompeu com o racionalismo clássico e, ao mesmo tempo, mostrou que a razão é mutável. Como, segundo o autor, a Teoria da Relatividade estabeleceu uma síntese entre o pensamento racional e a experiência técnica, como se verá mais adiante, o filósofo francês também intitula a nova base de pensamento da física de racionalismo dialético.?

Bachelard (1972) compara o impacto causado pelos conceitos da física relativista com a "revolução copernicana" operada por Kant na metafísica no século XVIII, que, ao subverter a relação sujeito-objeto, deslocou do real para o espírito as condições de possibilidades para o conhecimento. Foi mediante esse empreendimento filosófico pelo qual o filósofo de Königsberg edificou seu idealismo transcendental e estabeleceu uma síntese entre as teorias dos conhecimentos racionalista e empiristas modernas.

Entretanto, para o "filósofo da ruptura", a síntese elaborada por Kant não foi suficiente para dissolver o antagonismo entre ambas as teorias do conhecimento: "o empirismo e o racionalismo permaneceram, cara a cara, sem poder, na verdade, cooperarem filosoficamente, sem poder se enriquecer mutuamente" (BACHELARD, 1972, p. 130). Porém, no século XX, com a Relatividade, recomeça um novo diálogo entre a filosofia do real e a filosofia da razão.

Então, para Bachelard (1972, p. 134), "a filosofia kantiana deve ser substituída por uma filosofia dialética”. Ou seja, por uma filosofia que dialetiza teoria e experiência, que estabelece um diálogo entre espírito e coisas, e coisas e espírito (Cf. BACHELARD, 1966, p.12). Aqui, consiste a essência do projeto epistemológico bachelardiano, qual seja, a ideia de instituir um novo racionalismo, o racionalismo aplicado, não apenas como a filosofia mais adequada para fundamentar a física contemporânea, mas também como uma forma de superação das filosofias tradicionais.

No racionalismo aplicado há uma relação abstrato-concreta, isto é, uma união entre o pensamento matemático e as técnicas experimentais da física contemporânea. Trata-se de um "[...] nó onde a álgebra se une com a organização da experiência, onde a álgebra pensa a experiência” (BACHELARD, 1965, p. 29).

Desse modo, a revolução de Einstein estabeleceu uma síntese mais profunda em relação à "revolução copernicana" operada por Kant. O filósofo francês ainda acrescenta que a ruptura conceitual empreendida pela Relatividade consistiu de uma só vez a um aniquilamento de três séculos, não apenas de concepções realistas, como também de ideias racionalistas - como as de Kant acerca das noções (BACHELARD, 1972).

\footnotetext{
${ }^{9}$ Cabe notar que as expressões racionalismo culto, racionalismo complexo e racionalismo dialético são termos que se referem à essência mesma do racionalismo aplicado como a nova filosofia da física.
} 
É notável que Bachelard, mediante o advento da Teoria da Relatividade, procura demonstrar filosoficamente que a razão possui uma história descontínua, na medida em que ela possui uma atividade "turbulenta e agressiva" (Cf. BACHELARD, 1972, p. 13) contra suas próprias ideias instituídas historicamente. Por conseguinte, contemporaneamente, a razão já não pode ser simplesmente arquitetônica, de estrutura fixa, fechada e absoluta como pretendeu Kant em sua Crítica da razão pura (1781/1787).

\section{O ERRO DE MICHELSON COMO MOTOR DO CONHECIMENTO}

Bachelard (1972, 1977) atribui ao advento da mecânica relativista um aspecto consoante com a sua filosofia, qual seja, o de que a teoria de Einstein nasce de um erro intelectual, e por conseguinte de um fracasso experimental. Isso favorece à Relatividade uma interpretação filosófica inédita, uma vez que Bachelard se contrapõe a uma interpretação cumulativo-continuísta bastante propagada em sua época (como as concepções positivistas), impossibilitando qualquer análise que pretenda estabelecer a física newtoniana como o germe da física relativista.

Segundo Bachelard (1972, 1977), foi o experimento malogrado de Michelson acerca da possibilidade de calcular a velocidade da Terra em relação ao éter que possibilitou que a física acordasse de seu "sono dogmático", inspirando Einstein a compor a Teoria da Relatividade Restrita.

"Erro, tu não és um mal" (BACHELARD, 1977, p. 298). Essa frase em La formation de l'esprit scientifique (1938) procura apresentar o erro como o "motor do conhecimento", pois através dele se fornece os meios pelos quais é possível a superação de conhecimentos equivocados. Dessa forma, o fracasso experimental de Michelson deve ser interpretado como um fato positivo, porquanto libertou a física de um hábito racional, isto é, na crença da suposta existência do éter, sedimentada no pensamento científico e filosófico que remonta a Aristóteles. ${ }^{10}$

O erro de Michelson pôde ser considerado positivo na medida em que ele deu um tratamento racional ao seu experimento. Tratou-se de uma experiência inteligente (BACHELARD, 1972, 1977), isto é, o fracasso experimental de Michelson, de saída, evidenciou que o problema não se encontrava na experiência, mas nos pressupostos racionais.

Então, é possível dizer que a Teoria da Relatividade surge, nesse contexto, como o produto desse erro positivo pelo qual se estabeleceu um ato epistemológico (Cf. BACHELARD, 1965, p. 25), um avanço brusco no saber, em suma, uma superação de um obstáculo arraigado na cultura filosófico-científica que abriu novas possibilidades de compreensão do real.

Cabe notar que a interpretação de Bachelard a respeito do advento da Relatividade não se trata de uma concepção sui generis, porquanto físicos e

\footnotetext{
${ }^{10}$ Para uma melhor compreensão acerca da questão do erro, pode-se conferir Bachelard (1977, p. 297-306), Velanes (2018, p. 100-121) e Barone (1963, p. 453-476).
} 
filósofos de sua época compartilhavam dessa mesma ideia. Segundo Thuillier (1994), ainda na primeira metade do século XX ocorria um debate efervescente aceca da gênese da teoria de Einstein de 1905. Consideramos esclarecedora a seguinte explicação do autor quando destaca que embora Millikan, Petzoldt e Bachelard sejam teóricos com campo de pressupostos distintos, ainda assim apresentaram concepções praticamente idênticas acerca da relação entre o erro experimental de Michelson e o surgimento da teoria einsteiniana a qual se apresentava como resposta a um novo fato. Citando Thuillier (1994) extensamente:

Millikan fez a seguinte declaração: "Pode-se considerar que a teoria da relatividade restrita tem sua origem essencialmente numa generalização da experiência de Michelson." E, acrescentava, Einstein é um verdadeiro cientista porque "rejeitou todas as concepçoes a priori referentes à natureza da realidade". A experiência de Michelson-Morley fora concebida para pôr em evidência o deslocamento da Terra em relação ao éter; mas seus resultados sempre foram negativos. Ainda segundo Millikan, Einstein só precisava deste fato: "Einstein nos lançou então esse apelo: Aceitemos simplesmente isso como um fato experimental estabelecido, e a partir daí tratemos de extrair dele as inevitáveis conseqüências [...]. Assim nasceu a teoria da relatividade restrita". Esta interpretação, com algumas variantes, volta e meia aparece. Para o positivista Joseph Petzoldt, a teoria da relatividade confirmava o fracasso da velha metafísica. Só contavam os fatos: "A teoria einsteiniana depende inteiramente do resultado da experiência de Michelson e pode ser derivada dele". Gaston Bachelard, cuja epistemologia "dialética" está bem distante do positivismo, usa, entretanto, uma linguagem não muito diferente: "A relatividade nasceu de um choque epistemológico: ela nasceu do 'fracasso' da experiência de Michelson". Foi esta última que "arrancou a mecânica clássica de seu sono dogmático"; foi ele também que "serviu de base para a muito vasta generalização" de Einstein. (THUILLIER, 1994, p. 237-238).

Se de um lado Thuillier (1994) observa que físicos, historiadores e filósofos acreditem que o experimento de Michelson tenha sido o ponto de partida para o surgimento da física relativista, por outro ele não deixa de ressaltar que “(...) essa maneira de explicar a gênese da Teoria da Relatividade é muito discutível e, talvez, totalmente equivocada" (p. 238). O argumento do autor é que o próprio Einstein teria contribuído para ambiguidades de interpretação, ora exprimindo certa influência do "experimento" como decisiva para a sua teoria, ora demonstrando que pouco sabia acerca da experiência deste (Cf. THUILLIER, 1994, p. 239-240).

De qualquer forma, ainda que na interpretação de Bachelard acerca da origem da Relatividade não se leve em consideração as afirmações de Einstein a respeito da relevância ou irrelevância do fracasso do experimento de Michelson em sua teoria, o filósofo francês acreditava que a Relatividade consistiu em uma ruptura epistemológica como superação de uma ideia errônea tornada explicita mediante esse experimento. 


\title{
CONSIDERAÇÕES FINAIS
}

O que de fato nos parece relevante da investigação de Bachelard sobre a Relatividade é que ele encontra nesta teoria não só o fundamento de uma das revoluções/rupturas em direção um novo espírito científico, mas também a relação da física com a matemática como projeção do mundo, bem como a estipulação e criação de fenômenos que fazem da mecânica de Einstein uma teoria diferencial.

Tal iniciativa, é, em outras palavras, meta-ontológica, por estabelecer uma relação cosmológica do universo imbricada com uma organização matemática que coloca um retorno reflexivo da própria ontologia frente a sua regionalidade com outras ciências, pela qual a matemática pode consistir em um elo de ligação entre os conjuntos de saberes. E aí está a vigência da Teoria da Relatividade e a possibilidade de diálogo com outros campos da física contemporânea.

Outro ponto que convém observar é que tanto no artigo La dialectique philosophique des notions de la relativité (1949) como no capítulo segundo de Le nouvel esprit scientifique (1934), Bachelard não põe em discussão o caráter indutivo da relatividade, que é argumentação exposta em La valeur inductive de la relativité (1929). Nesta obra, o autor informa que a indução não tem o sentido clássico do termo, como aquele dado pelos empiristas, mas o sentido de construção. Trata-se de uma indução matemática que possibilita a construção do real e que "significa uma ruptura com a tese realista ao afirmar que não existe uma realidade a ser encontrada, mas a ser construída numa interação entre os pressupostos teóricos e empíricos" (CARVALHO FILHO, 2016, p. 94). Bachelard (1929) explica que:

\begin{abstract}
Não será, em primeiro lugar, uma prova de que o sistema não está contido nos seus postulados, pronto para a explicação, apto para a dedução, mas que, pelo contrário, o pensamento que o anima se coloca resolutamente perante uma tarefa construtiva, onde ele procura os complementos, as associações, toda a diversidade que faz nascer a preocupação de precisão? Por outras palavras, a novidade relativista não é na sua essência estática; não são as coisas que vêm surpreender-nos, mas é o espírito que constrói a sua própria surpresa e que se envolve no jogo das questões. A Relatividade é mais do que uma renovação definitiva na maneira de pensar o fenômeno físico, ela é um método de descoberta progressivo. (BACHELARD, 1929, p. 6).
\end{abstract}

Acerca dessa citação, concordamos com Carvalho Filho (2016, p. 95) quando explica que, para Bachelard, o objeto científico não é explicado pela Teoria da Relatividade, mas construídos a partir desta teoria. A mecânica einsteiniana apresenta em seu método os aspectos dedutivo e indutivo (construtor do real), na medida em que "a partir de formulações matemáticas, o cálculo tensorial, por exemplo, é possível inferir uma realidade por meio dos objetos matemáticos que se caracterizam por sua permanência".

Acrescentamos, ademais, uma observação não destacada por Carvalho Filho (2016, p. 95), qual seja, de que a relação entre dedução e indução na Relatividade, constatada pelo filósofo francês em sua obra de 1929 prefigura sua noção de 
racionalismo aplicado a que já nos referimos neste trabalho. Assim como em Essai sur la connaissance approchée (1928), o livro La valeur inductive de la relativité (1929) não apresenta a expressão dessa noção bachelardiana, embora seja possível perceber nas argumentações contidas nessas duas obras a essência desse conceito central da epistemologia bachelardiana. Em síntese, a partir dessas considerações, podemos afirmar junto a Bulcão (2009, p. 75) que "o racionalismo aplicado de Bachelard é um racionalismo indutor".

A Teoria da Relatividade exige novos fundamentos que possam representar seus conceitos. Com isso, as filosofias imobilistas, como as de Kant, Meyerson e Bergson, não podem acompanhar a evolução do saber científico, uma vez que determinam a razão como absoluta. É através dessas constatações que Bachelard informa seu projeto em oferecer à física contemporânea uma filosofia mais adequada.

Assim, quando o "filósofo da ruptura" propõe certa "submissão" da filosofia científica perante o saber das ciências, ainda que essa ideia possa evocar uma concepção de cunho positivista (sistema ao qual Bachelard critica de modo contundente), qual seja, a de reduzir a filosofia a uma mera disciplina das ciências, esta seria uma análise bastante superficial, uma vez que, pelo contrário, Bachelard atribui ao saber filosófico uma autonomia capaz de julgar a própria história das ciências.

Com efeito, a filosofia científica bachelardiana faz dialogar duas disciplinas diferentes, a epistemologia e a história das ciências, criando, dessa forma, um novo campo de conhecimento que fez tradição no pensamento filosófico francês, intitulado "epistemologia histórica" (LECOURT, 1978), ou "história epistemológica" (CANGUILHEM, 1979) ou ainda "epistemologia trans-histórica" (BONTEMS, 2017). Em suma, Bachelard procura oferecer às ciências contemporâneas, em especial à física, "a filosofia que ela merece", por isso entrega ao saber filosófico o poder próprio dessa forma de pensamento, que é a sua capacidade crítica e renovadora par excellence.

\section{REFERÊNCIAS}

ALUNNI, Charles. Spectres de Bachelard - Gaston Bachelard et l'école surrationaliste. Paris: Ed. Hermann, 2018.

BACHELARD, Gaston. La valeur inductive de la relativité. Paris: J. Vrin, 1929.

La pensée axiomátique. Études philosophiques. Paris, 1940.

. Les aspects philosophiques de la relativité. Hommage à Albert Einstein. Bobinografia. Institut Nationale du Audiovisuel (INA FRANCE): 23 de Avril 1955.

Le matérialisme rationnel. Paris: PUF, 1963.

. L'activité rationaliste de la physique contemporaine. Paris: PUF, 1965.

Le rationalisme appliqué. Paris: PUF, 1966.

. L'engagement rationaliste. Paris: PUF, 1972.

SOFIA (ISSN 2317-2339), ViTÓRIA (ES), V.9, N.1, P. 220-237, JAN./JUL. 2020 
BACHELARD, Gaston. La formation de l'esprit scientifique. Paris: J. Vrin, 1977. La philosophie du non. Paris: PUF, 1983. A dialética da duração. São Paulo: Ática, 1994. Le nouvel esprit scientifique. Paris: PUF, 1999. A intuição do instante. Campinas: Verus Editora, 2010.

BARONE, Francesco. "Verità" ed "Errore" nell' epistemologia di Gaston Bachelard. Revue Internationale de Philosophie. Vol. 17, n. 66 (4), 1963, p. 453-476.

BONTEMS, Vincent. Bachelard. São Paulo: Estação Liberdade, 2017.

BULCÃO, Marly. O racionalismo da ciência contemporânea: introdução ao pensamento de Gaston Bachelard. São Paulo: Ideias \& Letras, 2009.

CANGUILHEM, Georges. Études d'histoire et de philosophie des Sciences: concernant les vivants et la vie. Paris: Vrin, 1979.

CARVALHO FILHO, Ernane. Bachelard e o caráter indutivo da Teoria da Relatividade. Ensaios Filosóficos. Volume 13, 2016, p. 87-97.

EINSTEIN, Albert. Teoria da relatividade especial e geral. Rio de janeiro: Contraponto, 1999.

; INFELD, Leopold. A evolução da física. Jorge Zahar Editor. Rio de Janeiro, 2008.

HEISENBERG, W. Physics and philosophy: the revolution in modern science. New York: Happer Collins Publishers, 2007.

LACLOS, Fredéric. Bachelard et la valeur réaliste de la relativité. Bulletin. n. 7, 2005, p. $47-67$.

LECOURT, Dominique. L'epistémologie historique de Gaston Bachelard. Paris: Vrin, 1978.

MEYERSON, Émile. Identité et réalité. Paris: J.Vrin, 1951.

PATY, Michel. Einstein ou a criação científica do mundo. São Paulo: Estação Liberdade, 2008.

THUILLIER, Pierre. De Arquimedes a Einstein: a face oculta da invenção científica. Rio de Janeiro: Jorge Zahar Editor, 1994, cap. VIII.

VELANES, David. Gaston Bachelard e o progresso do saber. Rio de Janeiro: Multifoco, 2018.

Recebido em: 28-08-2019

Aceito para publicação em: 04-05-20 